\section{Da reformulação discursiva a uma práxis da cultura científica: reflexões sobre a divulgação científica}

\section{From discursive reformulation to praxis of scientific culture: reflections on science communication}

Guilherme da Silva Lima

i Professor, Instituto de Ciências Exatas e Biológicas/ Universidade Federal de Ouro Preto.

Ouro Preto - MG - Brasil

orcid.org/0000-0002-0049-5790

glima@ufop.edu.br

\section{Marcelo Giordan ${ }^{i i}$}

ii Professor, Faculdade de Educação/Universidade de São Paulo. São Paulo - SP - Brasil

orcid.org/0000-0002-4646-0139

giordan@usp.br
LIMA, Guilherme da Silva; GIORDAN, Marcelo. Da reformulação discursiva a uma práxis da cultura científica: reflexões sobre a divulgação científica. História, Ciências, Saúde - Manguinhos, Rio de Janeiro, v.28, n.2, abr.-jun. 2021, p.375392.

Resumo

Abordam-se as principais interpretações usadas para compreender a divulgação científica como reformulação do discurso científico e como um gênero discursivo próprio. Ambas as interpretações são analisadas criticamente, uma vez que as características do discurso de divulgação científica não são equivalentes aos parâmetros para a tradução, nem compatíveis com os critérios para compreendê-lo como um gênero discursivo próprio. Por fim, ressalta-se que a divulgação científica deve ser compreendida como práxis objetivada por atividades desenvolvidas em meio a diversas esferas de criação ideológica.

Palavras-chave: divulgação científica; reformulação discursiva; gênero do discurso; esfera de criação ideológica.

Abstract

This article addresses the main interpretations employed to understand science communication as a discursive reformulation of scientific discourse and as a genre of discourse of its own. Both these interpretations are analyzed critically, since the characteristics of the discourse of science communication are not equivalent to translation parameters nor compatible with criteria to understanding them as a component of their own discursive genre. Finally, it is emphasized that science communication should be understood as praxis objectified through activities developed amidst diverse spheres of ideological creation.

Keywords: science communication, discursive reformulation, genre of discourse, sphere of ideological creation. 
A divulgação científica (DC) tem sido cada vez mais produzida em nossa sociedade. Com a revolução comunicacional promovida pelas novas tecnologias, a DC está sendo veiculada em grande escala por meio de diversos suportes e destinada a públicos variados. Tal produção tem, especialmente, duas origens motivacionais: setores da sociedade que exigem cada vez mais a divulgação e circulação do conhecimento técnico-científico; a comunidade científica, que busca legitimação de sua prática social, bem como ampliar as formas de interlocução com a sociedade.

Apesar do volume de produções classificadas como DC, não há consenso entre os pesquisadores da área sobre a natureza dessa produção. A interpretação da DC como uma reelaboração discursiva está presente em diversos estudos (Bueno, 1985; Authier-Revuz, 1999; Epstein, 2012) e ainda figura como uma das principais interpretações dessa prática. De acordo com essa interpretação, a DC é entendida como uma espécie de tradução ou simplificação discursiva, que tem origem em um discurso fonte (discurso da ciência) e é destinada à produção de uma linguagem familiar.

Por outro lado, após 2000, desenvolveu-se a interpretação da DC como um gênero discursivo próprio, especialmente após o trabalho de Zamboni $(1997,2001)$. De acordo com a autora, a DC possui estruturas composicionais, unidades temáticas e estilos próprios, havendo, portanto, a produção de uma nova forma discursiva.

Com o intuito de contribuir para o debate e a reflexão acerca do conceito de DC, este trabalho discute alguns dos argumentos apresentados por essas perspectivas buscando desconstruir a ideia que concebe a DC como uma reformulação discursiva ou uma espécie de tradução de um discurso fonte - o discurso científico ${ }^{1}$-, bem como se posiciona criticamente quanto à interpretação da DC como um gênero discursivo próprio. O objetivo deste artigo é, portanto, fazer uma crítica às formas de conceber a DC e apresentar outra abordagem para interpretá-la. Diante das diversas interpretações que cercam a DC, pode-se notar o embate de perspectivas. Esse é um terreno fértil para reflexão e debate acerca da natureza da DC e merece destaque, uma vez que pode contribuir para melhorar a compreensão dessa atividade e, consequentemente, fomentar a produção de novas práticas e estratégias para a comunicação pública da ciência.

\section{A divulgação científica como reelaboração discursiva}

Tradicionalmente, o discurso de divulgação científica (DDC) foi compreendido como sendo simplificação, reelaboração ou reformulação do discurso científico. Polino e Castelfrachi (2012, p.361-362; destaques no original) ${ }^{2}$ enfatizam a origem da interpretação da DC como tradução:

A especialização do conhecimento científico e sua linguagem; a divisão do trabalho intelectual em disciplinas cada vez mais separadas, formalizadas e abstratas; a necessidade política e epistêmica de demarcação de fronteiras; o surgimento das 'massas'; a emergência de um mercado para a informação (e divulgação), ao longo do século XIX, converteram a divulgação da ciência em sinônimo de 'tradução', 'simplificação' de um conhecimento produzido por poucos (e acessível a poucos), mas direcionado às massas, constituídas por indivíduos aparentemente incompetentes 
e incapazes de alcançar a verdade por si mesmos, ou de participar ativamente na produção de conhecimento.

Authier-Revuz (1999) é uma das representantes da interpretação da DC como reformulação. A autora compreende a DC como conjuntos de práticas de reformulação, que se "designa continuamente como dois exteriores, o discurso científico fonte e o discurso familiar do grande público, entre os quais ela [DC] se coloca em cena como atividade de reformulação" (p.10).

A autora aponta que a DC é produzida por uma estrutura triádica, que diminui as discrepâncias entre o discurso científico e o familiar. Essa estrutura comporta três agentes: os especialistas, o público e o divulgador da ciência. Assim, os divulgadores científicos endereçam ao público conceitos e aspectos da cultura científica e tecnológica propostos pelos cientistas. É o divulgador, portanto, o sujeito responsável pela produção da DC.

Tal processo de simplificação fica mais claro quando a autora compara a atividade do divulgador da ciência com a atividade de tradução:

No nível do fio do discurso, é a comparação com a tradução que me parece a mais esclarecedora: o divulgador é frequentemente representado como um perito em tradução, a quem é necessário recorrer em virtude de uma ruptura de comunicação na sociedade; mas no lugar em que a tradução, por um trabalho de vaivém entre as duas línguas, de busca de equivalente, de tateamentos etc., produz um texto segundo que, homogeneamente em língua chegada, substitui um texto da língua fonte, a D.C. representa, em discurso, a colocação em contato de dois discursos, constrói uma imagem da tradução em andamento, através de um fio de discurso explicitamente heterogêneo. Este fenômeno, absolutamente massivo, realiza-se através de duas estruturas principais: a justaposição de dois discursos, sobre a cadeia, por numerosas formas de estabelecimento de equivalência (A, ou seja, B; A significando, batizado de B; A ou B etc.); o distanciamento metalinguístico alternativamente de um e de outro discurso, designado, com uma flagrante densidade pelo itálico ou pelas aspas como exterior, inapropriado (Authier-Revuz, 1999, p.12).

Essa interpretação evidencia a função do divulgador que, nesse contexto, tem papel fundamental: tornar assuntos acerca da ciência e da tecnologia inteligíveis ao público, uma vez que esse sujeito é responsável por traduzir uma linguagem específica para uma linguagem comum aos interlocutores, cuja consequência é massificar o acesso ao conhecimento científico.

Pesquisadores brasileiros também compactuam com essa vertente. Bueno (2009, p.162) esclarece que "a divulgação científica pressupõe um processo de recodificação, isto é, a transposição de uma linguagem especializada para uma linguagem não especializada, com o objetivo primordial de tornar o conteúdo acessível a uma vasta audiência".

Epstein (2012), ao formular uma teoria da divulgação científica, evidencia a comunicação científica como duas modalidades possíveis: comunicação interpares, também chamada de comunicação primária, e a comunicação pública ou divulgação científica, também conhecida por comunicação secundária. Segundo o autor, apenas "o discurso interpares dos cientistas é stricto sensu autônomo" (p.21); por outro lado, a divulgação científica ou a comunicação secundária é constituída em função do discurso científico. 
A relação entre a DC e o discurso científico, no entanto, ocorre por intermédio do divulgador, que, assim como nas propostas de Authier-Revuz e Bueno, possui papel central no processo de DC. Para Epstein (2012, p.30; destaque no original), que segue a mesma linha, "o divulgador necessita 'traduzir' uma mensagem formulada num código específico e unívoco, cujo acesso demanda um determinado tempo de aprendizado de seu usuário, o cientista, da linguagem natural, polissêmica e ambígua".

Tal interpretação não apenas segrega o principal sujeito da DC como também acentua os extremos dessa cadeia comunicativa, que é composta pelos especialistas (sábios) em um extremo e o público (ignorante) no outro. Assim, o divulgador da ciência tem o papel de aproximar o discurso do especialista e o discurso do leigo.

\section{Teorias da tradução}

Para fundamentar a crítica, é importante ressaltar o que tradução e reformulação discursiva significam. A tradução é objeto de muitas discussões, que visam à delimitação do conceito. Historicamente, há um embate entre duas perspectivas: a tradução literal e a tradução livre. A tradução literal defende a neutralidade, a objetividade e a fidelidade para com a mensagem do discurso fonte; ao contrário da tradução livre, que se baseia na parcialidade, subjetividade e infidelidade para com a mensagem original (Souza, 1998).

Roman Jakobson (citado em Souza, 1998) aponta a existência de três tipos de tradução: intralingual ou reformulação, baseada na interpretação por meio de signos da mesma língua; interlingual ou tradução propriamente dita, interpretação de signos verbais por meio de outra língua; intersemiótica ou transmutação, baseada na interpretação de signos verbais por meio de signos não verbais. Nesse sentido, ao interpretar a DC como reformulação discursiva, é necessário considerá-la uma tradução intralingual e mesmo intersemiótica, uma vez que signos próprios das ciências, como gráficos, esquemas, imagens etc. podem ser expressos no modo verbal em suportes de DC.

Outras interpretações relevantes acerca da tradução a concebem tanto como um processo de substituição de significados quanto um processo de produção de sentidos. Na primeira, há a substituição de significados de uma língua para outra; todavia, a principal crítica dessa perspectiva destaca que o significado é uma propriedade da língua, assim, textos de línguas diferentes podem ter significados que não são passíveis de tradução. Por outro lado, a tradução pode ser interpretada como a produção de equivalentes próximos à mensagem, respeitando em primeiro lugar a significação e, em seguida, o estilo (Souza, 1998).

A compreensão da tradução como produção de sentidos está fortemente embasada na interpretação do tradutor, visto que a interpretação de um texto/discurso depende de uma série de fatores linguísticos e não linguísticos. De acordo com Souza (1998, p.56-57): “Com base nessa perspectiva, já que todo tradutor é, antes, um leitor, toda tradução terá que ser, em primeiro lugar, um processo de identificação e de interpretação/produção de significados, em relação à compreensão leitora do texto original e, em segundo lugar, um processo de substituição e de produção de significados em relação ao texto de chegada". Desse modo, a tradução ocorre por meio de processos simultâneos de substituição de significados e de produção de significados. 
Esqueda (1999) também contribui para essa discussão com sua reflexão sobre a ética da tradução. Para a autora, há uma concepção predominante acerca da tradução que estabelece fidedignidade da tradução com seu respectivo original, bem como neutralidade do tradutor. Posição que critica fortemente: "A imposição de que o tradutor não deve utilizar seus conhecimentos para desfigurar ou alterar o original parece estar simplistamente fundamentada na ingenuidade, na inocência de que é possível haver tradução sem interpretação, sem uma leitura, sem interferência, sem alteração" (p.52).

Tal crítica tem grande impacto, visto que questiona a atividade de tradução. Também entendemos que a fidedignidade é algo impossível na tradução, uma vez que essa atividade requer necessariamente um processo de compreensão do enunciado, que, de acordo com Bakhtin (2009), é um processo ativo no qual o sujeito que compreende (ou está em processo de compreensão) se posiciona em relação ao enunciado e cria correspondências entre as suas palavras e as alheias (Lima, 2020).

Além disso, compreensão e produção discursivas são processos determinados por contextos históricos e culturais; momentos que a tradução nem sempre é capaz de apreender. Esse aspecto também é destacado por Esqueda (1999, p.53): “Desde que determinado texto implique uma tradução, o desencontro com sua origem, tempo, espaço, circunstâncias sócio-culturais é inevitável, fazendo com que a tentativa de repetição do mesmo não se concretize e tampouco se torne um dever ético. Por mais simples que seja, qualquer texto a ser traduzido pressupõe interpretação, alteração, interferência".

Além dessa concepção baseada na fidedignidade, há outras interpretações para compreender a tradução. Souza (1998) pontua que concepções desconstrutivistas também contribuíram para a compreensão da tradução. O desconstrutivismo destaca a leitura e a tradução como processos essencialmente subjetivos. Em uma análise extrema é possível inferir a impossibilidade de qualquer tradução, pois a interpretação subjetiva do indivíduo desconstrói a originalidade do discurso fonte e passa a enunciar um discurso próprio e autônomo.

Por mais diversas que sejam as contribuições e críticas para compreender a atividade de tradução, entendemos que as perspectivas estão baseadas na tensão entre dois elementos: a forma e o conteúdo. Todavia, independentemente da perspectiva, não nos parece pertinente nem correto considerar a DC uma modalidade de tradução: a reformulação; visto que a DC não manifesta diversas características do discurso científico seja na forma ou no conteúdo, conforme veremos a seguir.

\section{Crítica à tradução como forma de produção da divulgação científica}

Se considerada como forma de reelaboração discursiva, a DC se caracteriza pela tradução de um discurso específico, restrito aos poucos iniciados nos campos científicos, para um discurso generalista, capaz de atingir determinado grupo social.

Com relação à forma, é evidente que a DC não mantém a estrutura narrativa e sintática do discurso científico. É importante destacar que o objeto da DC não se restringe à suposta tradução de artigos ou de um discurso fonte. Nesse caso, o que seriam de colunas, blogs, exposições e cafés científicos? Essas atividades geralmente não estão centradas em 
determinados textos/discursos, mas sim na diversidade de ideias, conceitos, práticas e cenários que produziram, produzem ou representam a ciência.

Em relação ao jornalismo científico, modalidade de DC que, muitas vezes, conta com um discurso-fonte, Grillo e Olímpio (2006) apresentam resultados relevantes que evidenciam a possibilidade de diferentes estruturas composicionais entre o discurso de DC e o discurso científico. Segundo as autoras:

o texto de divulgação científica na esfera jornalística segue uma ordenação inversa ao texto científico (objetivos, procedimentos, conclusões, aplicações) e que a captação do leitor se dá sob a presunção do seu interesse pelos resultados e aplicações das pesquisas mais do que pelo próprio saber científico construído. O parágrafo se constitui na principal articulação composicional da reportagem, cada um podendo sintetizar o que corresponderia a uma seção inteira de um artigo científico (Grillo, Olímpio, 2006, p.389).

Além da variação da estrutura composicional, podemos citar ainda o uso de metáforas, analogias e outras figuras de linguagens que são frequentemente utilizadas pelo discurso de DC e raramente pelo discurso científico.

Outro aspecto relevante que influencia a alteração da forma e suscita questionamentos acerca da equivalência dos significados refere-se aos princípios da linguagem científica e da linguagem cotidiana. Pressupondo a DC como tradução, cabe a pergunta: como traduzir saberes expressos em linguagens (científica e popular) que possuem princípios estruturantes distintos? Como traduzir uma linguagem científica estruturalmente unívoca perante os significados para uma linguagem popular essencialmente polissêmica?

Devemos admitir que a forma adquirida pelo discurso é determinada pela linguagem utilizada. Não nos referimos somente às estruturas gramaticais como a posição de substantivos, adjetivos, pronomes, verbos etc., mas aos fundamentos lógicos e à produção de significados em uma determinada forma simbólica. As diferenças entre a linguagem científica e a linguagem cotidiana são muitas. Cassirer (2005), ao propor uma filosofia das formas simbólicas, contribui significativamente para compreender a diferença entre essas linguagens. Ao discutir acerca da linguagem cotidiana, o autor aponta que:

As classificações que encontramos na fala humana tampouco são feitas ao acaso; são baseadas em certos elementos constantes e recorrentes de nossa experiência sensorial. Sem tais recorrências não haveria um suporte, um ponto de apoio, para os nossos conceitos linguísticos. Mas a combinação ou a separação dos dados da percepção depende da livre escolha de uma estrutura de referência (Cassirer, 2005, p.220).

Destarte, a percepção tem papel fundamental na produção de significados e na classificação da linguagem cotidiana, algo que tende a ser rechaçado pelo conhecimento científico e, consequentemente, pela linguagem científica. Da mesma forma, as fontes de referência para sujeitos não comprometidos com os princípios de funcionamento da ciência são diversas e, muitas vezes, conflitantes com as fontes de referência da ciência. Nesse sentido, o autor destaca:

Os termos da fala comum não podem ser medidos pelos mesmos padrões que aqueles com que expressamos conceitos científicos. Comparados com a terminologia científica, 
os termos da fala comum apresentam sempre um caráter um tanto vago; quase sem exceção, eles são tão distintos e mal definidos que não resistem à prova da análise lógica (Cassirer, 2005, p.221).

A polissemia é um fator determinante que diferencia a linguagem científica da linguagem cotidiana. Para fugir da polissemia da palavra, a ciência se estrutura por meio de uma terminologia própria e sistemática baseada no conceito. "A criação de uma terminologia sistemática não é, de modo algum, um aspecto acessório da ciência, e sim um de seus elementos inerentes e indispensáveis" (Cassirer, 2005, p.341).

Baseada em propostas pitagóricas, a ciência foi estruturada por meio da unidade do conceito. O conceito, por sua vez, é delimitado tal como o número é determinado para a matemática, que não é definido exclusivamente por seus elementos internos, mas ocupa uma posição em uma ordem sistemática. Em um contexto de números inteiros, pode-se delimitar a posição $n+1$ ou n-1, que é respectivamente sucessora e antecessora de $n$. Tal princípio de orientação não é visto na linguagem cotidiana, mas é a base estrutural do conhecimento científico, em que um conceito é concebido pelas relações que tem com outros conceitos. Desse modo, o conceito é estabelecido por um sistema conceitual, estrutura que funda uma nova natureza para o símbolo, visto que o número é concebido "como um simbolismo novo e poderoso que, para todos os propósitos científicos, é infinitamente superior ao da fala. O que encontramos nele não são mais palavras isoladas, mas termos que procedem segundo um único plano fundamental e, portanto, mostram-nos uma lei estrutural clara e definida" (Cassirer, 2005, p.345).

Os conceitos científicos não são em essência números, mas a linguagem científica produz uma estrutura baseada na unidade do significado, assim como um conjunto numérico. Desse modo, a linguagem científica tenta afastar a inexatidão da palavra por meio da posição que um conceito tem em um sistema teórico. Com isso, "a ciência não fala mais a língua da experiência sensorial comum, mas o idioma pitagórico. O simbolismo puro do número substitui e oblitera o simbolismo da fala comum" (Cassirer, 2005, p.349).

Em síntese, é possível notar as diferenças existentes entre a linguagem científica e a linguagem cotidiana não somente no que tange à estrutura composicional, isto é, à forma, mas também aos princípios estruturadores dessas formas simbólicas.

A permanência dos significados é outra característica que não é mantida na produção da DC, ou seja, os significados presentes na DC nem sempre são equivalentes aos conceitos científicos. Podemos evidenciar ao menos três aspectos dos significados e objetos discursivos que são transformados durante a produção da DC em relação às características do discurso científico: o ontológico, o epistemológico e o axiológico.

Claramente há a distinção entre a origem do conhecimento científico e a origem do conhecimento proposto pela DC, fato que por si indicia planos ontológicos distintos. Enquanto o conhecimento científico tem o Universo como objeto de referência, a DC faz da cultura científica seu objeto. Reconhecemos que a DC aborda aspectos do Universo (realidade), no entanto não o faz a partir dos mesmos modos semióticos que a ciência. Quando a DC versa sobre a realidade, isso acontece pelo prisma do conhecimento científico. Não é, portanto, a realidade em suas condições concretas o objeto da DC, mas a interpretação 
dessa realidade pela ciência. Além disso, é importante ressaltar que o universo de referência da DC não se limita aos discursos científicos, visto que contempla também os próprios contextos de produção da ciência e da tecnologia, portanto, a DC também pode se referir à história, filosofia ou sociologia da ciência.

A interpretação da cultura científica como o conjunto de todas as práticas, histórias, valores, objetos, relações sociais, sujeitos que atuam e quaisquer outros elementos que estão diretamente relacionados às atividades científicas e tecnológicas ou mesmo orientados para elas ou pelo uso de seus produtos e processos, expande significativamente as fronteiras de origem da ciência, pois a reposiciona como produção humana histórica e culturalmente situada. Esse conjunto de elementos está em constante interação com outras esferas da cultura humana, condição que corrobora para uma influência recíproca (Lima, 2016). O conceito de cultura científica, portanto, contempla tanto o sentido apontado por Santos (2009), que a entende como patrimônio humano estabelecido por saberes, valores, crenças, expectativas e ações referentes ao campo da ciência e da tecnologia, quanto o sentido atribuído por Godin e Gingras (2000, p.44) de que "a cultura científica e tecnológica é a expressão de todos os modos pelos quais os indivíduos e a sociedade se apropriam da ciência e da tecnologia".

As distinções não se restringem somente à origem, mas também aos métodos de validação, legitimidade e propósitos da constituição do conhecimento científico e da DC. Devemos ressaltar que o principal propósito da ciência é compreender o Universo com base em uma determinada racionalidade unívoca, ao contrário dos objetivos da DC, que estão mais próximos da legitimação social da cultura científica, bem como da enunciação de princípios, práticas e conceitos produzidos pela ciência e pela tecnologia. No entanto, influências externas às práticas da ciência têm sido reconhecidas sobretudo a partir do arcabouço teórico da indústria cultural (Lima, Giordan, 2014), o que decorre de relações complexas que se estabelecem entre a ciência e outras instituições humanas, responsáveis também pelo processo de legitimação junto à sociedade.

Assim, ainda que façam parte do rol de atividades desenvolvidas pela cultura científica, a DC e a produção científica estão orientadas para objetos distintos da realidade, não há como uma ser reelaboração da outra. Para ser reelaboração, no mínimo, há que se manter os objetos de referência e os propósitos da produção enunciativa, fato que não ocorre entre a DC e os enunciados gerados pela ciência destinados aos pares.

O aspecto epistemológico carrega consigo uma reformulação semântica. É possível observar que os significados dados aos conceitos pela DC são diferentes daqueles dados pela ciência. Não estamos pontuando casos de erros conceituais, mas sim de ressignificação de conceitos. Os conceitos contidos em suportes de DC são, em grande escala, simplificações de conceitos científicos que, muitas vezes, estão distantes das proposições científicas. Tal fato não descaracteriza o referente da DC, que continua sendo a cultura científica, mas preconiza um universo conceitual próprio.

A ausência do formalismo matemático é um exemplo da transformação ocorrida nos significados dos conceitos científicos. O formalismo matemático em si não constitui o conhecimento científico, mas oferece uma orientação particular para compreender a natureza e estruturar os conceitos. Nesse sentido, a matemática estabelece o horizonte de 
possibilidades e as fronteiras da reflexão. Quantas palavras seriam necessárias para explicar o que é e quais as implicações de uma equação diferencial parcial ou de um operador divergente ou rotacional, considerando que fosse possível compreender tais ferramentas sem o domínio da linguagem matemática?

A linguagem química e suas propriedades semióticas são outro exemplo da necessidade de construções semânticas próprias para se referir a propriedades de substâncias ou efeitos de reações químicas. O ente molecular ou as relações entre suas partes, na forma de ligações, têm exigido formas de representação que variam entre os conjuntos de autovalores e autovetores de funções de onda aos elementos gráficos de conexão, forma e posição. A fenomenologia da transformação da matéria forma um campo semântico próprio com construções simbólicas próprias, com nível de formalismo só acessível aos iniciados. Ainda assim, é possível considerar meios de interação entre diferentes campos, da mesma forma que ocorre na ciência.

A transformação semântica é um dos fatores que fundamenta a produção de um novo plano epistemológico. A distinção entre os diversos aspectos da cultura científica e da DC corrobora a produção de esferas epistemológicas diferentes. Assim, a estrutura dos conceitos e contextos abordados pela DC não está pautada na construção de um corpus teórico articulado para a compreensão de fenômenos e técnicas, mas sim para a enunciação de aspectos relacionados à cultura científica para determinado público.

As relações existentes entre os conceitos próprios do conhecimento científico estão voltadas para a totalidade do conjunto teórico, isto é, os conceitos, as técnicas e os métodos são articulados para constituir uma teoria coesa, de modo que os sentidos são produzidos dentro de um conjunto particular. Em contrapartida, na DC, as relações existentes entre os conceitos se limitam ao caso abordado, isto é, ao assunto e ao referente. Para exemplificar, podemos refletir sobre os geradores elétricos: no âmbito da ciência ou do conhecimento científico, tal assunto é concebido pelo eletromagnetismo, que pode ser compreendido por meio das equações de Maxwell, ${ }^{3}$ cujos principais conceitos são o campo elétrico e a indução magnética. A partir desses conceitos, todos os outros podem ser compreendidos, e, consequentemente, os geradores, explicados. Por outro lado, no âmbito da DC, a estrutura conceitual não é o fator mais importante para compreender os geradores, e faz-se uso de um conceito específico do conjunto teórico proposto pelo conhecimento científico (como o conceito de corrente induzida), associado frequentemente ao uso de contextualizações, analogias e exemplos para figurar o imaginário do público.

Em suma, as relações semânticas que são estabelecidas com os conceitos científicos pela DC nem sempre contemplam a estrutura teórica da ciência. Tal fato é consequência dos recortes delimitados pela DC, bem como a seleção da audiência e dos propósitos da atividade de divulgação.

Por fim, no aspecto axiológico, a DC tem como referente um objeto já legitimado por diversas esferas de produção da sociedade. Assim, a DC não se configura essencialmente como um espaço para o debate dos assuntos abordados visando questionar a autoridade da comunidade científica. Se pensarmos em casos recentes, como a descoberta de água em Marte ou a detecção do bóson de Higgs, que foram extensivamente cobertos pela mídia antes mesmo de uma validação maciça da comunidade científica, esses casos não são 
abordados pela DC para que a sociedade possa questioná-los, criticar os métodos ou refutar os resultados, mas sim como prestação de contas à sociedade. Trata-se, principalmente no bojo das produções influenciadas por princípios de funcionamento da indústria cultual, de uma relação unívoca com origem na ciência e a sociedade como destino. A DC, portanto, é produzida tendo em vista um objeto validado pela cultura científica. Não acreditamos que essa deva ser a estrutura da interação da DC com a sociedade, mas é essa estrutura que tem sido utilizada na maior parte dos casos, ainda que haja críticas no âmbito da produção acadêmica sobre DC.

$\mathrm{Na}$ maioria das vezes, a DC aborda assuntos e objetos que já foram publicados em periódicos científicos, pois se trata da divulgação de elementos da cultura científica que foram avaliados por pares. A avaliação por pares confere validade e legitimidade à investigação científica, em razão de o avaliador ter competência reconhecida em seu campo de pesquisa. Assim, a DC se apoia e tem como referentes: conclusões, métodos, práticas, histórias e contextos considerados coerentes e legítimos por um determinado campo de investigação. Em outras palavras, a legitimidade do referente coloca a DC em uma posição difícil para debater as controvérsias que ocorrem no âmbito da ciência.

O fato de contar com um objeto validado não acarreta uma prática comunicativa acrítica, em que a DC se comprometa exclusivamente com uma interpretação positiva da cultura científica, modelo que pode ser compreendido pelo enfoque clássico do jornalismo científico (Fioravanti, 2013). Entendemos que a orientação não é uma característica elementar da DC, isto é, ser um instrumento para promoção ou para a interpretação crítica da cultura científica não é uma propriedade determinante da DC, mas uma orientação ideológica que fundamenta determinada prática de DC. O que evidenciamos aqui é a incapacidade de a DC refutar ou mesmo reafirmar os resultados das pesquisas científicas. Ainda que seja capaz de tecer críticas apontando possíveis contradições, a refutação ocorrerá no nicho da comunicação científica entre pares. Sobre as orientações da DC, entendemos que aquelas que tentam reconhecer a ciência como um empreendimento humano inserido na história - portanto, determinadas pelos valores de sua época - e tentam contemplar as complexas relações sociais, bem como as rupturas e continuidades do desenvolvimento científico e tecnológico, são mais adequadas para a abordagem da cultura científica e para a promoção da atuação da sociedade na esfera da ciência e da tecnologia.

Assim, ao contrário das atividades que, para serem incluídas na cultura científica, precisam de legitimidade e validação de seus membros, a DC não possui tal característica. Não estamos falando apenas dos resultados científicos, mas de todos os métodos, atividades e assuntos estudados. Até mesmo a abordagem de temas controversos e a exposição de diversas perspectivas possuem essa particularidade, pois se trata de objetos da cultura científica, objetos legitimados e ainda em processo de compreensão.

Não havendo condições possíveis de generalizar a manutenção da forma e dos significados, somado à disparidade entre os planos ontológicos, epistemológicos e axiológicos que fundamentam a ciência e a DC, entendemos que compreender a DC como uma espécie de tradução é um equívoco. A DC não é a tradução de um discurso específico para um discurso familiar, seja ela compreendida como reformulação, tradução ou transmutação. 


\section{A divulgação científica como gênero discursivo}

Alguns pesquisadores questionaram a perspectiva mencionada e interpretaram a DC por meio do conceito de gênero discursivo (Zamboni, 2001; Leibruder, 2003; Cunha, 2009; Cunha; Giordan, 2009, 2015), cujas bases foram desenvolvidas a partir da crítica à interpretação da DC como reformulação discursiva.

Uma contraproposta à interpretação da DC como reformulação discursiva surge com Zamboni (1997, 2001), que a defende como um gênero discursivo próprio. A autora tece uma crítica acerca da proposição de Authier-Revuz, em que a DC constitui uma atividade de reformulação discursiva. Zamboni (2001, p.82) caracteriza "o discurso de DC como um gênero particular no conjunto dos demais discursos das diferentes áreas de funcionamento da linguagem, e não apenas como um gênero que particulariza no subconjunto das práticas de reformulação".

Para sustentar a argumentação, Zamboni (2001) se pauta nas contribuições de Bakhtin e compreende que a DC comporta enunciados relativamente estáveis do ponto de vista temático, composicional e estilístico. A autora aponta que, da perspectiva temática, o gênero DC é caracterizado pela concentração do assunto ciência e tecnologia. Em termos composicionais, ela destaca a "recuperação de conhecimentos científicos tácitos, fórmulas de envolvimento e segmentação da informação" (p.89), e, por fim, do ponto de vista estilístico, a autora indica o emprego de analogias, generalizações, aproximações, comparações, simplificações, que visam suprir as dificuldades de um público não especializado.

Tendo em vista que o enunciado é produzido socialmente por sujeitos organizados e que a existência de um destinatário é essencial para a produção discursiva, Zamboni (2001) avança significativamente ao tentar afastar a concepção de que a DC é produzida por atividades de reformulação ou uma espécie de tradução, uma vez que evidencia o sujeito destinatário da DC, e não somente o discurso fonte.

Na mesma perspectiva, Leibruder (2003) corrobora as contribuições de Zamboni quando defende que a DC é um gênero discursivo particular. A autora busca delinear as principais características dos discursos envolvidos: o discurso científico, o jornalístico e o de DC.

O discurso científico é produzido, segundo Leibruder (2003), por meio de uma estrutura rígida constituída pelos suportes utilizados, objetivos, procedimentos, resultados e conclusões. Além disso, destaca a formalidade, a objetividade e o padrão lexical do discurso científico que tende a apagar o sujeito por meio do emprego de sujeitos indeterminados (voz passiva) ou na primeira pessoa do plural. Tal composição, segundo a autora, visa produzir um caráter de neutralidade, impessoalidade e veracidade do discurso científico.

Já com relação ao discurso jornalístico, a autora o compreende como um discurso de transmissão de informação constituído por objetividade, clareza e concisão da linguagem. O discurso jornalístico, assim como o científico, também é marcado pela impessoalidade, o jornalista tenta se camuflar a fim de evidenciar o fato a ser noticiado que deve ocupar posição central. Apesar da impessoalidade, o discurso jornalístico faz uso de índices de subjetividade, ao passo que a escolha do estilo tem o intuito de atingir e se aproximar de determinadas audiências. 
Com relação ao discurso de DC, a autora aponta características como a aplicação de pressupostos teóricos, índices de objetividade e de subjetividade, elementos didatizantes, inclusão da voz do cientista para dar confiabilidade e veracidade e o apagamento do sujeito. Além disso, a autora defende que a DC não é um discurso segundo, ainda que exista uma etapa de reformulação: "a reformulação não deve ser considerada enquanto a razão última deste fazer discursivo, mas somente como uma das etapas por este percorrida, na medida em que o texto utiliza recursos didatizantes a fim de possibilitar ao público leigo o contato com conteúdos muitas vezes herméticos e inacessíveis" (Leibruder, 2003, p.235).

Apesar de considerar a suposta reformulação discursiva, a autora levanta outros argumentos que corroboram a adoção da DC como gênero discursivo. A alteração do cenário discursivo e das posições ocupadas pelos interlocutores, bem como a seleção de recursos linguísticos para contemplar os propósitos da DC e a sensibilização do público, torna a DC uma produção legítima e própria com características discursivas particulares, e não uma adaptação de outro discurso, isto é, faz da DC um discurso próprio.

Além dessas pesquisadoras, Grillo (2006a, 2006b), Cunha e Giordan (2009, 2015) e Cunha (2009) propõem interpretações que questionam a reformulação discursiva considerada pelos modelos tradicionais e utilizam as proposições do círculo de Bakhtin para compreender a DC.

$\mathrm{Na}$ esteira das reflexões acerca da natureza da DC, Cunha (2009) também concebe a DC como gênero discursivo e critica pontos como o apagamento do sujeito que, segundo a pesquisadora, não existe. Segundo ela, o apagamento do sujeito é puramente aparente, uma vez que o sujeito-autor se inscreve no discurso e deixa pistas decorrentes de suas percepções e concepções de ciência e tecnologia. A autora destaca que a DC é um gênero discursivo próprio e que as diferenças existentes entre suportes de DC ocorrem por adaptações do gênero, que variam de acordo com as características do público. Desse modo, a DC é produzida por meio de elementos narrativos cuja intensidade e inclusão variam em maior ou menor grau de acordo com os interlocutores presumidos. Tal fato visa ao envolvimento do público com a DC por meio da identificação com suas formas enunciativas.

Entender a DC como gênero discursivo permitiu novas abordagens para a pesquisa e produção desse suporte comunicacional; contudo, apesar da defesa da interpretação da DC como um gênero discursivo próprio, essa perspectiva também apresenta algumas limitações.

\section{Crítica à DC como gênero discursivo}

Grillo (2006b) aponta a dificuldade de estabelecer o que é a DC, seja como gênero discursivo, seja como atividade de reelaboração discursiva e atribui essa dificuldade às diversas esferas da atividade humana nas quais a DC transita. Baseada nos conceitos de "campo" e "esfera de criação ideológica", propostos por Bourdieu e Bakhtin respectivamente, a autora aponta que a DC transita em três campos: o científico, o educacional e o midiático. Ela destaca que:

A articulação das obras de Bourdieu e do círculo de Bakhtin permitiu-nos identificar as noções de campo e esfera como um domínio sociodiscursivo, caracterizado por um modo próprio de organização social e da linguagem, o que produz uma ordem específica de refração ou de tradução da base socioeconômica comum e dos outros 
campos da atividade humana. Essa refração ou transformação ocorre em razão das relações objetivas entre os agentes, as instituições, os gêneros discursivos e do diálogo entre as obras de um campo (Grillo, 2006b, p.62).

Por esse motivo, os discursos de DC podem sofrer coerções e influências desses três campos delineados. No âmbito das informações midiáticas, a autora destaca características como atualidade, periodicidade, objetividade e captação do leitor. Tal interpretação sugere também que a DC praticada nos campos científicos e educacionais possui características diferentes daquelas produzidas pelo campo midiático (Grillo, 2006b).

A interseção de esferas de atuação também é reconhecida por pesquisadores que entendem a DC como reformulação discursiva. Grigoletto (2005) apresenta contribuições ao propor que a DC é produzida em um espaço intervalar, onde se chocam sujeitos, saberes e instituições, fato que contribui para uma constituição heterogênea do discurso de DC. Em suma, a autora avança no que tange à interseção de esferas de atuação, que estão no terreno da ciência, da mídia e do senso comum; retoma, entretanto, a posição tradicionalmente defendida de que a DC tem como referente ou fundador o discurso da ciência.

No âmbito dos gêneros discursivos, Grillo (2006a) questiona o uso do conceito por Zamboni (2001). Para a autora, "a divulgação científica não é um gênero discursivo particular, mas realiza-se em diversos gêneros: reportagem, artigo, pergunta/resposta do leitor, editorial, manual, aula etc." (Grillo, 2006a, p.1829). Além disso, a DC não se restringe ao campo de transmissão de informações, ela se constitui na prática discursiva de três campos ideológicos, e salienta a autora que o assunto ciência e tecnologia não compreende o conceito de tema do gênero como proposto por Zamboni (2001).

O conceito "tema" proposto pelo círculo de Bakhtin é muito mais abrangente do que sua compreensão geral como assunto. Para Bakhtin (2010, p.133), "o tema da enunciação é na verdade, assim como a própria enunciação, individual e não reiterável. Ele se apresenta como a expressão de uma situação histórica concreta que deu origem à enunciação". Portanto, há um aspecto situacional a qualificar o conceito.

Medviédev (2012, p.197) também apresenta uma compreensão que converge para o sentido descrito acima: "a unidade temática da obra é inseparável de sua orientação original na realidade circundante, isto é, inseparável das circunstâncias espaciais e temporais". Grillo (2006a, p.1828), por sua vez, defende que "o tema não é uma propriedade da estrutura frasal, mas é composto no todo da obra, na sua relação com as circunstâncias temporais e espaciais, em suma, na situação de comunicação concreta".

O conceito de tema, portanto, é compreendido não somente pelos elementos verbais, mas por todos aqueles que circunscrevem a enunciação em um momento histórico concreto. Como a produção da DC ocorre em diversos momentos históricos, é pouco provável haver uma unidade temática congruente nas enunciações produzidas. A grande variedade de contextos de produção da DC, que articulam diversos motivos e campos do conhecimento, determina a existência de tantos outros "temas".

A crítica tecida por Grillo (2006b) nos direciona a uma interpretação relevante, visto que a DC não é um gênero discursivo particular. Cabe neste momento uma ampliação dessa discussão contemplando as contribuições de Bakhtin, especialmente o conceito de "gêneros discursivos". 
Bakhtin (2006, p.262) estabelece que os gêneros discursivos são "tipos relativamente estáveis de enunciados". De modo que são classificados em duas modalidades: os gêneros primários e os secundários. Os primários são produzidos essencialmente em situações cotidianas sob as condições de interação imediata; por outro lado, os secundários são produzidos em situações culturais mais complexas. Tomando a DC como atividade expressa por gêneros discursivos, trata-se de um gênero secundário, que geralmente é produzido sob as influências dos gêneros científicos, midiáticos e familiar, sendo este último escolhido de acordo com a audiência.

O autor sustenta ainda que os gêneros discursivos são produzidos na articulação de três características: a unidade temática, a estrutura composicional e o estilo. Assim, a combinação dessas características do enunciado é capaz de gerar diversos gêneros discursivos. O gênero discursivo, no entanto, não pode ser compreendido especificamente no plano do enunciado. Sua compreensão se estende para as condições macrossociais em que a interação verbal é produzida.

Para entender tais condições, cabe evidenciar a noção de "esfera de criação ideológica". Bakhtin (2006, p.266) destaca que os gêneros são delimitados também pelas esferas de criação ideológica nas quais foram produzidos; em suas palavras, "uma determinada função e determinadas condições de comunicação discursiva, específicas de cada campo, geram determinados gêneros, isto é, determinados tipos de enunciados estilísticos, temáticos e composicionais relativamente estáveis".

Se tomarmos a DC como objeto da reflexão, é possível verificar que sua origem está centrada na cultura científica, uma vez que ela não é apenas seu referente, mas constitui, sobretudo, uma maneira de ver, interpretar e interagir com o mundo. Desse modo, não é possível produzir DC sem a existência de uma cultura científica, conforme também defende Vogt (2012).

Concebemos, portanto, a DC como uma prática que se materializa por meio de gêneros discursivos e tem como referente a cultura científica. No que tange aos contextos de produção, há a necessidade de evidenciar os propósitos da DC: genericamente, a DC busca estabelecer interações entre a cultura científica e a sociedade por meio da abordagem de aspectos conceituais, metodológicos, históricos, filosóficos ou sociais da ciência, da tecnologia e suas histórias.

\section{Como compreender a DC?}

Nesse contexto, é importante destacar que só é possível divulgar ciência se houver algum aspecto da cultura científica para ser divulgado. Com isso, não queremos defender um processo comunicativo unívoco, mas evidenciar que o objeto discursivo seja passível de comunicação, isto é, não há comunicação sem referente. Se não há uma cultura científica parcialmente estruturada, não há DC.

Essa reflexão nos leva a outra, que está baseada na origem da DC. Os modelos tradicionais para compreender a DC evidenciam o divulgador da ciência e o papel da mídia para a produção da DC. Tal concepção está fortemente presente nas interpretações acerca da DC que fomentam sua compreensão como uma tradução do discurso científico para um discurso acessível à população, concepção que apresentamos como equivocada. 
Nas concepções tradicionais de DC, a posição do divulgador e a representatividade dos meios de comunicação indicam que a DC é produzida na esfera midiática. Essa compreensão, todavia, extrai as características do universo de referência da cultura científica e compreende a DC como uma atividade exclusiva da comunicação.

Defendemos que a DC é produzida pela esfera da cultura científica em colaboração com outras esferas de atividades humanas. Assim, a DC é um produto gerado na interseção de esferas de criação ideológicas, cujas atividades disputam motivos, propósitos, regras, agentes, ferramentas culturais, entre tantos outros elementos (Lima, 2016). Em uma análise a partir da cultura científica, teremos a apropriação da comunicação, do jornalismo, da mídia e suas técnicas como ferramentas culturais para a produção da DC, enquanto o universo de referência, os princípios e os valores continuam sendo próprios da cultura científica. Por outro lado, se partirmos da esfera da mídia, teremos a apropriação de conhecimentos, fatos e histórias da ciência, enquanto as formas de produção do suporte são próprias da esfera midiática. Podemos estender esse exercício para todas as esferas que atuam na DC, como a educação, por exemplo, e provavelmente encontraremos análises coerentes, condição que reforça nossa compreensão de que a DC é produzida em meio à interseção da cultura científica com outras esferas de atuação humana.

Ainda que sejam produzidas em interseções, existem algumas características da DC que estão alocadas especialmente na cultura científica, como é o caso dos divulgadores. Sejam cientistas, jornalistas, professores ou quaisquer outros agentes, os divulgadores transitam em diferentes esferas de criação ideológica e, após a produção da DC, são publicamente representantes da cultura científica, pois são responsáveis por ampliar o diálogo entre a cultura científica e diversos públicos. Independentemente do modo de atuação do divulgador, seja por meio de uma comunicação unívoca e positiva ou por meio de uma comunicação crítica da cultura científica, sua função social é determinada pela competência (capacidade) de mobilizar saberes, valores, processos, agentes etc. da cultura científica. Portanto, por ser o sujeito que toma como referente a cultura científica e promove o diálogo com outras esferas da atividade humana, consideramos que o divulgador científico é um representante da cultura científica. Ressaltamos que essa consideração é essencial para compreender de forma mais ampla a cultura científica, uma vez que evidencia um sujeito de atuação abrangente nos processos comunicativos da ciência e da tecnologia.

É importante destacar que cada esfera ideológica tem suas próprias características e, segundo Bakhtin (2010, p.33), "tem seu próprio modo de orientação para a realidade e refrata a realidade à sua própria maneira. Cada campo dispõe de sua própria função no conjunto da vida social". Assim, por mais que as esferas midiática e educacional possam exercer coerções e influenciar a produção da DC, tal como aponta Grillo (2006b), essas influências são incapazes de deturpar princípios e valores contidos na cultura científica que é o referente da DC.

A produção da DC deixa indícios claros que vão além da forma estrutural do enunciado, pois contempla ou tenta contemplar os signos, bem como a ideologia científica. Bakhtin (2010, p.37) salienta ainda que: "Cada um dos demais sistemas de signos é específico de algum campo particular da criação ideológica. Cada domínio possui seu próprio material ideológico e formula signos e símbolos que lhe são específicos e que não são aplicáveis a 
outros domínios. O signo, então, é criado por uma função ideológica precisa e permanece inseparável dela".

Assim, ainda que existam coerções e interseções com outros campos, não há como deslocar princípios ontológicos da cultura científica que são inerentes aos conceitos, metodologias e práticas da ciência. Fato que sustenta e fortalece a interpretação do divulgador como um representante da cultura científica. A DC, portanto, é produzida em meio a uma interseção de esferas de criação ideológica; a cultura científica, no entanto, exerce maior influência sobre o produto gerado. Tal concepção evidencia que a interseção na qual a DC é produzida não é composta por esferas equipolentes. Ainda que a cultura científica tenha maior influência na determinação dos produtos da DC, trata-se de um produto gerado em meio a disputas, cujos escopos variam de acordo com os suportes de DC e os meios de comunicação em que são veiculados. Não é preciso ser um especialista em DC para notar as diferenças entre veículos de DC que, por vezes, sustentam coerções da indústria cultural e, por isso, usufruem livremente do sensacionalismo, da fetichização do conhecimento científico, visando ao aumento das vendas, e publicações que claramente têm interesses de ensinar conceitos científicos que estão fortemente baseados em coerções provenientes da educação científica (Lima, Giordan, 2014).

A DC, nesse contexto, passa a ser compreendida como práxis, isto é, como uma "unidade de teoria e prática, como ação consciente, como prática que se baseia na (e se funde com a) reflexão crítica" (Burgos, 2019, p.98). A prática de divulgar ciência é realizada por meio de atividades (entendidas aqui como a objetivação da práxis) desenvolvidas na interação de esferas de criação ideológicas, e não exclusivamente como um processo comunicativo que visa transmitir informações ou mensagens a sujeitos que não têm acesso a elas. É importante destacar que as esferas de criação ideológicas não produzem especificamente a DC. Elas constituem a superestrutura (no sentido dado por Marx) para a atividade humana. A atividade do divulgador é o motor da produção da DC; sem sujeito e sem atividade não haveria DC, mesmo que houvesse cultura científica.

Nesse sentido, a interpretação exclusivamente por meio das características linguísticas e discursivas deve ser superada para que a área se atente a outros elementos da prática de divulgar a cultura científica e compreenda criticamente o vasto campo da DC. Tal consideração não deve ser interpretada como uma defesa da abolição das investigações sobre elementos linguísticos e discursivos, que continuam sendo essenciais para compreender as diversas características da comunicação entre a cultura científica e a sociedade.

Por tudo que foi apresentado, ressaltamos a possibilidade de ao menos três novas perspectivas para o estudo da DC. A primeira orienta-se para as atividades da DC, buscando compreender sujeitos, objetos, instrumentos, regras, comunidades e a divisão social do trabalho, em suas múltiplas determinações na objetivação da atividade de divulgar a cultura científica. Uma introdução a tal orientação pode ser encontrada no trabalho de Lima e Giordan (2018). A segunda orienta-se para a investigação das relações entre as esferas de criação ideológica que compõem a DC, que, por sua vez, demandam aprofundamento dos conceitos de cultura e ideologia. Uma abordagem com esse viés foi realizada por Lima e Moschen (2018). Por fim, e não menos importante, a terceira perspectiva para a investigação da DC está direcionada para compreender as relações entre as atividades, as ideologias e a 
cultura humana. Essa via pode ser particularizada na investigação sobre as formas de DC produzidas em interação com as instituições de ensino e o papel que desempenham os representantes da cultura científica na enculturação crítica dessas audiências.

\section{AGRADECIMENTOS}

Ao CNPq pela bolsa de produtividade em pesquisa, processo n.308240/2019-7.

\section{NOTAS}

${ }^{1}$ Delimitaremos as expressões "discurso da ciência" e "discurso científico" como modalidades discursivas destinadas a pares, isto é, cujos propositores e destinatários participam da mesma esfera de produção. Portanto, as expressões referem-se a artigos, livros, palestras, entre outras atividades comunicativas que são produzidas pelos cientistas e a eles destinadas.

${ }^{2}$ Nessa e nas demais citações de textos em outros idiomas, a tradução é livre.

${ }^{3} \nabla \cdot \vec{B}=0$

$$
\begin{aligned}
& \nabla \times \vec{B}=\frac{\partial \vec{E}}{\partial t}+J \\
& \nabla \cdot \vec{E}=\rho \\
& \nabla \times \vec{E}=\frac{-\partial \vec{B}}{\partial t}
\end{aligned}
$$

${ }^{4}$ Nos livros de Bakhtin, o termo esfera também foi traduzido como campo e domínio e assim deve ser compreendido no caso de citações diretas. Destacamos que, no decorrer do texto, usaremos apenas o termo esfera para que compreensão não seja prejudicada.

\section{REFERÊNCIAS}

AUTHIER-REVUZ, Jacqueline. Dialogismo e divulgação científica. Rua: revista do núcleo de desenvolvimento da criatividade, n.5, p.9-15, 1999. Disponível em: https://periodicos.sbu.unicamp. br/ojs/index.php/rua/article/view/8640645. Acesso em: 27 abr. 2021.

BAKHTIN, Mikhail. Questões de literatura e de estética: a teoria do romance. São Paulo: Hucitec, 2010.

BAKHTIN, Mikhail. Marxismo e filosofia da linguagem. São Paulo: Hucitec, 2009.

BAKHTIN, Mikhail. Estética da criação verbal. São Paulo: Martins Fontes, 2006.

BUENO, Wilson. Jornalismo científico: revisitando o conceito. In: Victor, Celene; Caldas, Graça; Bortoliero, Simone. Jornalismo científico e desenvolvimento sustentável. São Paulo: All Print, 2009.

BUENO, Wilson. Jornalismo científico no Brasil: os compromissos de uma prática dependente. Tese (Doutorado) - Escola de Comunicação e Arte, Universidade de São Paulo, São Paulo, 1985.

BURGOS, Raúl. El concepto de objetividad en Gramsci. Tempo social, v.31, n.2, p.95-121, 2019.
Disponível em: https://doi.org/10.11606/01032070.ts.2019.157686.

CASSIRER, Ernest. Ensaio sobre o homem: introdução a uma filosofia da cultura humana. São Paulo: Martins Fontes, 2005.

CUNHA, Márcia Borin. A percepção de ciência e tecnologia dos estudantes do ensino médio e a divulgação científica. Tese (Doutorado) - Faculdade de Educação, Universidade de São Paulo, São Paulo, 2009. Disponível em: https://doi. org/10.11606/T.48.2010.tde-02032010-091909.

CUNHA, Márcia Borin; GIORDAN, Marcelo. Divulgação científica na sala de aula: implicações de um gênero. In: Cunha, Márcia Borin; Giordan, Marcelo. Divulgação científica na sala de aula: perspectivas e possibilidades. Ijuí: Editora Unijuí, 2015.

CUNHA, Márcia Borin; GIORDAN, Marcelo. A divulgação científica como um gênero de discurso: implicações em sala de aula. In: Encontro Nacional de Pesquisa em Educação em Ciências, 7. Anais... Florianópolis: UFSC, 2009.

EPSTEIN, Isaac. Comunicação da ciência: rumo a uma teoria da divulgação científica. Espaço 
aberto, v.9, n.16-17, p.19-38, 2012. Disponível em: https://doi.org/10.11606/issn.2238-2593. organicom.2012.139126

ESQUEDA, Marileide Dias. Teorias de tradução e a questão da ética. Mimesis, v.20, n.1, p.49-55, 1999.

FIORAVANTI, Carlos Henrique. Um enfoque mais amplo para o jornalismo. Intercom - RBCC, v.36, n.2, p.315-332, 2013. Disponível em: https://doi. org/10.1590/S1809-58442013000200015.

GODIN, Benoit; GINGRAS, Yves. What is scientific and technological culture and how is it measured? A multidimensional model. Public Understand of Science, v.9, n.1, p.43-58, 2000. Disponível em: https://doi.org/10.1088/09636625/9/1/303.

GRIGOLETTO, Evandra. O discurso da divulgação científica: um espaço discursivo intervalar. Tese (Doutorado em Letras) - Universidade Federal do Rio Grande do Sul, Porto Alegre, 2005.

GRILLO, Sheila Vieira de Camargo. A noção de 'tema do gênero' na obra do Círculo de Bakhtin. Estudos linguísticos, v.35, p.18251834, 2006a. Disponível em: http://www.gel. hospedagemdesites.ws/estudoslinguisticos/ edicoesanteriores/4publica-estudos-2006/ sistema06/1136.pdf. Acesso em: 9 mar. 2021.

GRILLO, Sheila Vieira de Camargo. Divulgação científica na esfera midiática. Intercâmbio, v.15, p.1-10, 2006b. Disponível em: https://revistas. pucsp.br/index.php/intercambio/article/ view/3691. Acesso em: 9 mar. 2021.

GRILLO, Sheila Vieira de Camargo; OLÍMPIO, Ariadne Mattos. Gêneros do discurso e ensino. Filologia e Linguística Portuguesa, v. 8, p.379-390, 2006. https://doi.org/10.11606/issn.2176-9419. v0i8p379-390.

LEIBRUDER, Ana Paula. O discurso de divulgação científica. In: Brandão, Helena Nagamine. Gêneros do discurso na escola: mito, conto, cordel, discurso político, divulgação científica. São Paulo: Cortez, 2003.

LIMA, Guilherme da Silva. O conceito de compreensão em Bakhtin e o Círculo: reflexões para pensar o processo educativo. Bakhtiniana: Revista de Estudos do Discurso, v.15, n.3, p.297-317, 2020. Disponível em: https://doi. org/10.1590/2176-457348458.

LIMA, Guilherme da Silva. O professor e a divulgação científica: apropriação e uso em situações formais de ensino. Tese (Doutorado em Educação) - Faculdade de Educação/Universidade de São Paulo, São Paulo, 2016. Disponível em: https://doi. org/10.11606/T.48.2016.tde-16082016-093959.
LIMA, Guilherme da Silva; GIORDAN, Marcelo. O movimento docente para o uso da divulgação científica em sala de aula: um modelo a partir da teoria da atividade. Revista Brasileira de Pesquisa em Educação em Ciências, v.18, n.2, p.493-520, 2018. Disponível em: https://doi. org/10.28976/1984-2686rbpec2018182493.

LIMA, Guilherme da Silva; GIORDAN, Marcelo. Entre o esclarecimento e a indústria cultural: reflexões sobre a divulgação do conhecimento científico. In: Tavares, Denise; Rezende, Renata (org.). Mídias e divulgação científica: desafios e experimentações em meio à popularização da ciência. Rio de Janeiro: Ciências e Cognição, 2014. p.12-32.

LIMA, Guilherme da Silva; MOSCHEM, Mariana. Orientações ideológicas nas informações científicas: o caso da abordagem do rompimento da barragem de Fundão presente na revista Veja. Journal of Science Communication América Latina, v.1, n.1, p.1-18, 2018. Disponível em: https://doi.org/10.22323/3.01010204.

MEDVIÉDEV, Pável Nikoláievitch. O método formal nos estudos literários: introdução crítica a uma poética sociológica. São Paulo: Contexto, 2012.

POLINO, Carmelo; CASTELFRACHI, Yurij. Comunicación pública de la ciencia. Historia, prácticas y modelos. In: Aibar, Eduard; Quintanilla, Miguel Ángel. Enciclopedia iberoamericana de filosofía: ciencia, tecnología y sociedad. Madrid: Trotta, 2012.

SANTOS, Maria Eduarda. Ciência como cultura: paradigmas e implicações epistemológicas na educação científica escolar. Química Nova, v.32, n.2, p.530-537, 2009.

SOUZA, José Pinheiro. Teorias da tradução: uma visão integrada. Revista de Letras, n.20, v.1/2, p.51-61, 1998. Disponível em: http://www. revistadeletras.ufc.br/rl20Art09.pdf. Acesso em: 8 mar. 2021.

VOGT, Carlos. The spiral of scientific culture and cultural well-being: Brazil and IberoAmerica. Public Understanding of Science, $\mathrm{v}$. 21, n.1, p.1-13, 2012. Disponível em: https://doi. org/10.1177/0963662511420410.

ZAMBONI, Lilian Márcia Simões. Cientista, jornalista e a divulgação científica: subjetividade e heterogeneidade no discurso de divulgação científica. Campinas: Autores associados, 2001.

ZAMBONI, Lilian Márcia Simões.

Heterogeneidade e subjetividade no discurso da divulgação científica. Tese (Doutorado) - Instituto de Estudos da Linguagem, Universidade Estadual de Campinas, Campinas, 1997.

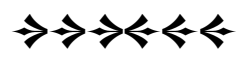

